\begin{tabular}{|c|c|}
\hline Title & $\begin{array}{l}\text { Population genetic structure of Microdochium majus and Microdochium nivale associated with Fusarium head blight of } \\
\text { wheat in Hokkaido, Japan }\end{array}$ \\
\hline Author(s) & Hayashi, Y .; Kozawa, T.; A iuchi, D.; Koike, M.; A kino, S.; Kondo, N. \\
\hline Citation & $\begin{array}{l}\text { European journal of plant pathology, 140(4), 787-795 } \\
\text { https://doi.org/10.1007/s10658-014-0509-3 }\end{array}$ \\
\hline Issue Date & $2014-12$ \\
\hline Doc URL & http:/hdl.handle.net/2115/57837 \\
\hline Rights & The final publication is available at www.springerlink.com \\
\hline Type & article (author version) \\
\hline File Information & Population genetic structure of Microdochium majus ... .pdf \\
\hline
\end{tabular}

Instructions for use 


\section{Population genetic structure of Microdochium majus and Microdochium nivale associated with Fusarium head blight of wheat in Hokkaido, Japan}

Hayashi Y, Laboratory of Plant Pathology, Graduate School of Agriculture, Hokkaido University, Sapporo 060-8589, Hokkaido, Japan

Kozawa T, Hokkaido Research Organization Tokachi Agricultural Experiment Station, Obihiro 082-0081, Hokkaido, Japan

Aiuchi D, Department of Agro-environmental Science, Obihiro University of Agriculture and Veterinary Medicine, Obihiro 080-8555, Hokkaido, Japan

Koike M, Department of Agro-environmental Science, Obihiro University of Agriculture and Veterinary Medicine, Obihiro 080-8555, Hokkaido, Japan

\footnotetext{
Akino S, Laboratory of Plant Pathology, Research Faculty of Agriculture, Hokkaido University, Sapporo 060-8589, Hokkaido, Japan
}

Kondo N, Laboratory of Plant Pathology, Research Faculty of Agriculture, Hokkaido University, Sapporo 060-8589, Hokkaido, Japan

Correspondence to: Norio Kondo

Laboratory of Plant Pathology, Research Faculty of Agriculture, Hokkaido University, Sapporo 060-8589, Hokkaido, Japan

Tel.: +81-11-706-3829 
Fax: +81-11-706-4938

E-mail: norikon@ res.agr.hokudai.ac.jp 


\section{Abstract}

Microdochium majus and Microdochium nivale are two of fungal pathogens that cause Fusarium head blight (FHB) in wheat, and have also caused pink snow mold in eastern Hokkaido, Japan. With the aim of assessing levels of genetic variation and population structure, 172 isolates of these Microdochium species obtained from five populations of infected wheat seeds were first classified into each species using polymerase chain reaction (PCR) amplification with specific primers. In total 165 (95.9\% of all isolates) and seven isolates (six of Tokachi populations and one of Abashiri populations) were identified as $M$. majus and $M$. nivale, respectively, indicating that $M$. majus was predominant and the main causal pathogen of FHB in this area. Inter-simple sequence repeat (ISSR) analysis showed that the total genetic diversity was 0.023 when estimated by Nei's gene diversity index within the five populations dominated by M. majus. An AMOVA analysis also showed that $86.74 \%$ of the total genetic variation was within populations and $13.26 \%$ among populations. These results indicated that little genetic differentiation occurred among the five populations of $M$. majus. Based on the unweighted pair group method of cluster analysis using the ISSR data, all isolates were identified as one of eight haplotypes in $M$. majus or six haplotypes in $M$. nivale, allowing the construction of a dendrogram with two clades corresponding to each species. There was no correlation between the clustering of isolates and their geographic distribution on the tree. These findings show that migration is likely playing an important role in the population biology of $M$. majus, providing some support for the prediction of epidemics of fungicide resistant strains within populations of the FHB pathogen.

\section{Keywords}

Microdochium majus, Microdochium nivale, genetic diversity, population structure, ISSR marker, Fusarium head blight. 


\section{Introduction}

Microdochium nivale (Fr.) Samuels \& I.C. Hallett sensu lato, which is currently classified into Microdochium majus and Microdochium nivale sensu strict (Glynn et al. 2005), is one of several pathogens that can cause leaf blotch and Fusarium head blight (FHB) in the cereals of Hokkaido, Japan. In particular, pink snow mold is often a serious disease in eastern Hokkaido. It causes pre-emergence damping-off when infected wheat seeds are sown in the field, resulting in seedlings with brown lesions on their roots and leaves (Millar and Colhoun 1966).

Microdochium nivale identified by Samuels and Hallett (1983) was initially identified as Fusarium species (Wollenweber and Reinking 1935) and further divided into two varieties; M. nivale var. majus and M. nivale var. nivale (Gerlach and Nirenberg 1982). Several studies suggested that there were greater differences in biological and ecological properties between two varieties; host preference (Lees et al. 1995; Diamond and Cooke 1997; Mahuku et al. 1998; Simpson et al. 2002), greater virulence of M. nivale var. nivale to grasses (Grosch and Schumann 1993) versus greater virulence of M. nivale var. majus to cereals (Maurin et al. 1995; Diamond and Cooke 1997), and higher isolation frequency of M. nivale var. majus from grains (Lees et al. 1995; Parry et al. 1993). In addition, the presence of the two varieties has been demonstrated using molecular techniques such as random amplified polymorphic DNA (RAPD) analysis (Lees et al. 1995); restriction fragment length polymorphism (RFLP) analysis based on the internal transcribed spacer (ITS) region (Parry et al. 1993); esterase isozymes and ITS polymorphisms (Maurin et al. 1995); and sequence analysis based on the gene encoding elongation factor 1-a (EF-1a) (Glynn et al. 2005).

Moreover, M. nivale var. nivale has shown many polymorphisms within the variety (Lees et al. 1995), indicating that this variety can reproduce sexually in nature (Lees et al. 1995). In contrast, $M$. nivale var. majus exhibits a high level of genetic uniformity, indicating that this 
variety generally reproduces homothallically in nature (Lees et al. 1995). Analysis of the DNA sequences of RNA polymerase II (RPB2), $\beta$-tubulin, and elongation factor from these varieties supported the recent elevation of $M$. nivale and M. majus to sister species (Jewell and Hsiang 2013). The RPB2 sequences also resolved both the North American and European $M$. majus isolates and M. nivale isolates from either turfgrasses or wheat into separate clades.

Inter-simple sequence repeat (ISSR) is a PCR-based technique that involves the amplification of DNA sequences between simple sequence repeats (SSR) by means of anchored or non-anchored SSR homologous primers (Zietkiewicz et al. 1994). ISSR does not require information about genome sequence in advance and can detect a greater number of polymorphisms than RFLP or RAPD (Godwin et al. 1997). ISSR is therefore an efficient tool for analysing genetic diversity within closely related species (Yu et al. 2008), and for studying genetic populations of fungi (Menzies et al. 2003; Chadha and Gopalakrishna 2007). The genetic diversity within or among pathogen populations leads to an understanding of how that pathogen has adapted to abiotic stresses, fungicides and plant resistance (McDonald and Linde 2002). Therefore, understanding the genetic diversity in populations of plant pathogenic fungi may prove useful in the improvement of disease management systems or in developing cultivars with tolerance and/or resistance to disease (Stenglein and Balatti 2006; Bayraktar et al. 2008). Despite its importance, there is little information about the genetic diversity and population structure of the Microdochium species isolated from Hokkaido.

The purpose of this study, therefore, was (i) to classify species, and (ii) to analyse the population genetic structure of Microdochium species isolates originating from geographically distant regions in Hokkaido. 


\section{Materials and Methods}

\section{Fungal isolates}

All 172 isolates were obtained from infected wheat seeds originating from geographically distant regions (Tokachi, Abashiri, Sorachi, Iburi and Shiribeshi) in Hokkaido, Japan, in 2011. The location and the number of isolates sampled from each population are listed in Table 1 and shown on the map (Fig. 1). Wheat seeds were harvested from fields in each region. Symptomatic seeds were plated on agar (WA; distilled water, 1 1; agar, $15 \mathrm{~g}$ ) containing streptomycin sulphate $(300 \mathrm{mg} / \mathrm{l})$, from which pure isolates were obtained using common methods of single spore isolation. Until use, all isolates were stored on agar plates at $5^{\circ} \mathrm{C}$ in the dark.

\section{DNA extraction}

Genomic DNA was extracted from 14-day-old cultures in potato dextrose broth (PDB, Difco) according to Saitoh's protocol (Saitoh et al. 2006). Mycelia were harvested from PDB and $500-\mu \mathrm{L}$ lysis buffer (400 mM Tris-HCl, $\mathrm{pH} 8.0 ; 60$ mM EDTA, $\mathrm{pH} 8.0 ; 150 \mathrm{mM} \mathrm{NaCl} ; 1 \%$ SDS) was added to a $1.5-\mathrm{mL}$ Eppendorf tube. The tube was incubated at room temperature for $10 \mathrm{~min}$, and then $150 \mu \mathrm{L}$ of potassium acetate $(\mathrm{pH} 4.8)$ was added (60-mL $5 \mathrm{M}$ potassium acetate plus $11.5-\mathrm{mL}$ glacial acetic acid) and the tube was vortexed briefly. Tubes were centrifuged for $5 \mathrm{~min}$ at $15,000 \mathrm{rpm}$ and then $300 \mu \mathrm{L}$ of the supernatant was transferred to a new tube. Ethanol $(750 \mu \mathrm{L}$ of $100 \%$ ethanol) was added and the new tube was centrifuged for $3 \mathrm{~min}$ at 15,000 rpm. After decanting the supernatant, $300 \mu \mathrm{L}$ of $70 \%$ ethanol was added and centrifuged for $5 \mathrm{~min}$ at 15,000 rpm. After decanting the supernatant, the precipitate was dried for 20-30 min and then resuspended in 50- $\mu \mathrm{L}$ TE $(10 \mathrm{mM}$ Tris- $\mathrm{HCl}, \mathrm{pH} 8.0 ; 1 \mathrm{mM}$ EDTA, pH 8.0). 


\section{Specific PCR amplification}

PCR reactions were performed in a total volume of $20 \mu \mathrm{L}$ containing $10 \times$ PCR buffer, 2.5 $\mathrm{mM}$ of dNTPs, $0.4 \mu \mathrm{M}$ forward and reverse primers, $1.25 \mathrm{U}$ of Taq DNA Polymerase (Takara, Japan), and 10-30 ng of genomic DNA. Primers used were those for $M$. nivale (Y13NF/R: CCAGCCGATTTGTGGTTATG/GGTCACGAGGCAGAGTTCG) (Nicholson et al. 1996) and $M . \quad$ majus (Mnm2F/R: TGCAACGTGCCAGAAGCT/ AATCGGCGCTGTCTACTAAAAGC) (Nicholson and Parry 1996). Amplification was performed in a Program Temp Control System PC-818 (ASTEC, Japan) with an initial denaturation step of $94^{\circ} \mathrm{C}$ for $2 \mathrm{~min}$; followed by 32 amplification cycles of $94^{\circ} \mathrm{C}$ for $30 \mathrm{~s}$, $55^{\circ} \mathrm{C}$ for $30 \mathrm{~s}$, and $72^{\circ} \mathrm{C}$ for $45 \mathrm{~s}$, with a final step of $72^{\circ} \mathrm{C}$ for $3 \mathrm{~min}$. Negative controls with no target DNA were included to test for the presence of DNA contamination in the reagent and reaction mixtures. Aliquots $(4 \mu \mathrm{L})$ of amplification products were electrophoresed on $2 \%$ agarose gels, and separated fragments were visualized under $300 \mathrm{~nm}$ UV light after staining with ethidium bromide.

\section{Genetic diversity using ISSR markers}

Extracted DNA was amplified using ISSR primers to estimate genetic diversity. Two primers, $(\mathrm{GTG})_{6}$ and $(\mathrm{ACA})_{6}$, that showed good repetition, special bands, and distinct polymorphisms, were chosen from 16 pre-screened primers. The PCR reactions were performed in a total volume of $20 \mu \mathrm{L}$ containing $10 \times$ PCR buffer, $2.5 \mathrm{mM}$ of dNTPs, $0.4 \mu \mathrm{M}$ of each primer, 1.25 U of ExTaq DNA Polymerase (Takara, Japan), and 10-30 ng of genomic DNA. Amplification was performed in a Program Temp Control System PC-818 with an initial denaturation step of $94^{\circ} \mathrm{C}$ for $2 \mathrm{~min}$; followed by 38 amplification cycles of $94^{\circ} \mathrm{C}$ for $30 \mathrm{~s}, 55^{\circ} \mathrm{C}$ for $30 \mathrm{~s}$ for $(\mathrm{ACA})_{6}$ or $60^{\circ} \mathrm{C}$ for $30 \mathrm{~s}$ for $(\mathrm{GTG})_{5}$, and $72^{\circ} \mathrm{C}$ for $45 \mathrm{~s}$; with a final extension at $72^{\circ} \mathrm{C}$ for 5 min. Negative controls with no target DNA were included to test for the presence of DNA 
contamination of the reagent and reaction mixtures. Aliquots $(4 \mu \mathrm{L})$ of amplification products were electrophoresed through $2 \%$ agarose gels, and separated fragments were visualized under $300 \mathrm{~nm}$ UV light after staining with ethidium bromide.

\section{Data analysis}

Because ISSR markers are dominant, we assumed that each band represented the phenotype at a single biallelic locus. The bands generated by ISSR primers that were repeatable and clearly visible with a high intensity were scored manually for the presence (1) or absence (0) of bands in each isolate. These data were analysed using the POPGENE software version 1.31 (Yeh et al. 1999) to estimate genetic diversity and the following population structure parameters: the percentage of polymorphic bands (PPB), effective number of alleles per locus $\left(A_{\mathrm{E}}\right)$ and average gene diversity $\left(H_{\mathrm{E}}\right)$. The coefficient of gene differentiation $\left(\mathrm{G}_{S T}\right.$; McDermott and McDonald 1993) was measured using Nei's method (Nei 1973). The level of gene flow $(\mathrm{Nm})$ was estimated as $0.5\left(1-\mathrm{G}_{S T}\right)\left(\mathrm{G}_{S T}\right)^{-1}$ (McDermott and McDonald 1993). An analysis of molecular variance (AMOVA) was also used to partition the total phenotypic variance within populations and among populations using the software Arlequin version 3.5 (Excoffier and Lischer 2010). To visualise the genetic relationships among populations, a dendrogram was constructed with the Neighbour unweighted pair group method of cluster analysis using arithmetic averages (UPGMA) using the software package PHYLIP (Phylogeny Inference Package, version 3.69; Department of Genetics, University of Washington, Seattle, WA, USA). 


\section{Results}

Classification with specific primers

All 172 isolates of Microdochium species obtained from infected wheat seeds were classified into the two species using PCR amplification with $\mathrm{Y} 13 \mathrm{NF} / \mathrm{R}$ and $\mathrm{Mnm} 2 \mathrm{~F} / \mathrm{R}$ primer pairs (Table 1). Of the 172 isolates, 165 of them produced a single band of $\sim 750 \mathrm{bp}$ from PCR amplification with $\mathrm{Mnm} 2 \mathrm{~F} / \mathrm{R}$, and seven isolates produced a single band of $~ 300 \mathrm{bp}$ using PCR amplification with Y13NF/R, which were the same size as expected by Nicholson and Parry (1996), respectively. Thus, the former was identified as M. majus, and the latter was identified as $M$. nivale. The isolates of $M$. nivale were only detected within Tokachi and Abashiri populations.

\section{Genetic diversity}

Two ISSR primers selected from 16 were used to investigate genetic diversity and population structure within 165 isolates of M. majus from wheat growing in different geographical origins. The ISSR primers produced a total of 22 replicated bands, of which 20 were polymorphic (Table 2). The size of amplified fragments ranged from 400 to $2000 \mathrm{bp}$ (Fig. 2). All 172 isolates from the five populations were identified as 14 ISSR haplotypes, designated as $\mathrm{H} 1$ to H14 (Table 3). The most detected haplotype in all populations was H2 of M. majus, representing $59.3 \%$ of the total isolates.

The percentage of polymorphic loci (PPB) was $27.3 \%$, whereas that of a single population ranged from $0 \%$ (Shiribeshi) to $15.0 \%$ (Tokachi and Sorachi), with an average of $10.0 \%$ (Table 4). Thus, PPB thorough populations showed relatively high uniformity among populations. The average effective number of alleles per locus $\left(A_{\mathrm{E}}\right)$ and the average gene diversity $\left(H_{\mathrm{E}}\right)$ of the Tokachi population were estimated to be relatively high compared with those of other populations. 


\section{Dendrogram analysis}

The dendrogram was constructed by the UPGMA from Nei's genetic distance values based on the ISSR data (Fig. 3). All haplotypes formed two clades that belonged to either M. majus or $M$. nivale. No significant correlation was found between geographic distribution and genetic distance on the UPGMA tree.

\section{Population structure}

The total gene diversity within the five populations of M. majus was 0.023 and the coefficient of gene differentiation $\left(\mathrm{G}_{S T}\right)$ was 0.13 . This value indicates that $13 \%$ of the observed genetic variation was due to gene differentiation among regional populations (Table 4). The average number of individuals exchanged among populations per generation $(\mathrm{Nm})$ was 3.334.

The AMOVA for regional populations showed that of the total genetic diversity, there were 0.05 variance components among populations and 0.32 within populations; $13.26 \%$ of the variance occurred among populations and $86.74 \%$ occurred among individuals within populations (Table 5). No significant $(\mathrm{P}<0.05)$ genetic differentiation was observed among the five populations. 


\section{Discussion}

This is the first report on the ISSR analysis of Microdochium species consisting of M. majus and $M$. nivale that permits apparent identification of the two species and investigates genetic diversity and population structure. ISSR markers are capable of the detection of a higher number of polymorphisms than are other molecular markers, such as RFLP or RAPD (Godwin et al. 1997). High-performance results with ISSR markers have been reported by several studies on population genetics. For example, ISSR analysis showed high intraspecific variability within the population of Fusarium poae, causing FHB from infected grains (Dinolfo et al. 2010). Therefore in this study, ISSR analysis was performed to investigate genetic diversity and population structure within 172 isolates of Microdochium species in winter wheat from five different geographical origins in Hokkaido island. All isolates were classified as two different species with specific primer pairs, Y13NF/R and Mnm2F/R, which permitted clear identification of M. majus and M. nivale. The majority of isolates $(95.9 \%)$ were identified as M. majus and each population showed a marked predominance of M. majus in the grains (Table 1). It was also reported in some studies that $M$. nivale var. majus (currently M. majus) was much more abundant than var. nivale (currently $M$. nivale sensu strict) in both grains and stem bases of winter wheat (Lees et al. 1995; Parry et al. 1993; Nielsen et al. 2013). In contrast, Terami and Kamikawa (2006) previously reported that 94.3\% of the isolates obtained from pink snow mold of winter wheat in Hokkaido were classified as $M$. nivale. This opposite result might indicate a correlation between host tissue origin and isolation frequency of species type under the environmental or ecological conditions in Hokkaido.

Genetic diversity in all populations of $M$. majus showed few differences and a high level of genetic uniformity among populations (Tables 4 and 5). The overall distribution of diversity within and among the five populations of M. majus in Hokkaido was assessed by using Nei's 
gene diversity index and AMOVA. The coefficient of gene differentiation $\left(\mathrm{G}_{S T}\right)$, based on Nei's gene diversity index, was very low. In addition, AMOVA showed that most molecular variations were found within rather than among the populations, indicating little genetic differentiation among the five populations. A high occurrence of polymorphisms within isolates of $M$. nivale than M. majus (described as $M$. nivale var. nivale and var. majus, respectively) has been reported (Lees et al. 1995) and all isolates originating from turfgrass were shown to be M. nivale with very high levels of genetic diversity (Mahuku et al. 1998). Further surveys for genetic diversity in $M$. nivale as well as M. majus in Hokkaido would clarify the genetic structure of Microdochium species.

Some studies have reported that seed dispersal is a primary factor influencing variation in gene flow and population structure (Kalisz et al. 1999). Besides seed dispersal, we hypothesised that the high level of gene flow observed in this study might be responsible for the dispersal ability of airborne spores of the fungi to distant areas. Little is known about how far these spores can be dispersed in air. Moreover, this dispersal ability might have contributed to the rapid development of thiophanate methyl-resistant strains of Microdochium species in Hokkaido in which the fungicide has been used widely for the control of FHB complex. These resistant strains were first reported in Hokkaido in 1981 (Tanaka et al. 1983) and have been spreading rapidly throughout the prefecture. Therefore, further research on the dispersal ability of airborne spores will be needed in the future. In addition, the emergence and spread of fungicide resistance including strobilurins (unpublished data) in Microdochium species should also be examined through more detailed population structure studies within and among populations of Microdochium species in different geographical origins.

Based on the ISSR data, there is a distinct resolution between $M$. majus and M. nivale as in the previous reports (Glynn et al. 2005; Jewell and Hsiang 2013), and each of all 172 isolates from the five populations was identified as one of eight ISSR haplotypes of M. majus or six 
ISSR haplotypes of $M$. nivale. The Tokachi population showed the highest haplotype diversity, followed by Sorachi and Abashiri (Table 3). According to the dendrogram, there was no correlation between the clustering of isolates and the geographic distribution on the tree (Fig. 3). These findings confirmed previous reports that ISSR is an efficient tool for analysing genetic diversity within closely related species (Yu et al. 2008), and that it provides a rapid and easy method for DNA fingerprinting (Bornet and Branchard 2001).

In conclusion, this study has demonstrated that ISSR is an efficient tool for genetic diversity and population structure studies of $M$. nivale and M. majus. The high level of genetic uniformity among M. majus populations and the higher gene flow showed that migration is likely playing an important role in the population biology of M. majus, providing some support for the prediction of epidemics of fungicide resistant strains within populations of the FHB pathogen. 


\section{References}

Bayraktar, H., Dolar, F. S., \& Maden, S. (2008). Use of RAPD and ISSR markers in detection of genetic variation and population structure among Fusarium oxysporum f. sp. ciceris isolates on chickpea in Turkey. Journal of Phytopathology, 156, 146-154.

Bornet, B., \& Branchard, M. (2001). Nonanchored inter simple sequence repeat (ISSR) markers: reproducible and specific tools for genome finger- printing. Plant Molecular Biology Reporter, 19, 209-215.

Chadha, S., \& Gopalakrishna, T. (2007). Comparative assessment of REMAP and ISSR marker assays for genetic polymorphism studies in Magnaporthe grisea. Current Science, 93, 688-692.

Diamond, H., \& Cooke, B. M. (1997). Host specialisation in Microdochium nivale on cereals. Cereal Research Communications, 25, 533-538.

Dinolfo, M. I., Stenglein, S. A., Moreno, M. V., Nicholson, P., Jennings, P., \& Salerno, G. L. (2010). ISSR markers detect high genetic variation among Fusarium poae isolates from Argentina and England. European Journal of Plant Pathology, 127, 483-491.

Excoffier, L., \& Lischer, H. E. L. (2010). Arlequin suite ver. 3.5: a new series of perform population genetics analyses under Linux and Windows. Molecular Ecology Resources, $10,564-567$.

Gerlach,W., \& Nirenberg, H. (1982). The Genus Fusarium - a Pictorial Atlas. Paul Verlag, Berlin Germany.

Glynn, N. C., Hare, M. C., Parry, D. W., \& Edwards, S. G. (2005). Phylogenetic analysis of EF-1 alpha gene sequences from isolates of Microdochium nivale leads to elevation of varieties majus and nivale to species status. Mycological Research, 109, 872-880.

Godwin, I. D., Aitken, E. A., \& Smith, L. W. (1997). Application of inter simple sequence repeat (ISSR) markers to plant genetics. Electrophoresis, 18, 1524-1528. 
Grosch, R., \& Schumann, K. (1993). Aggressivitätsverhalten von Microdochium nivale Samuels U. Hallett an futtergräsern. Archives of Phytopathology and Plant Protection, 28, 139-146.

Jewell, L. E., \& Hsiang, T. (2013). Multigene differences between Microdochium nivale and Microdochium majus, Botany, 91, 99-106.

Kalisz, S., Hanzawa, F. M., Tonsor, S. J., Thiede, D. A., \& Voigt, S. (1999). Ant-mediated seed dispersal alters pattern of relatedness in a population of Trillium grandiflorum. Ecology, 80, 2620-2634.

Lees, A. K., Nicholson, P., Rezanoor, H. N., \& Parry, D. W. (1995). Analysis of variation within Microdochium nivale from wheat: evidence for a distinct sub-group. Mycological Research, 99, 103-109.

Mahuku, G. S., Hsiang, T., \& Yang, L. (1998). Genetic diversity of Microdochium nivale isolates from turfgrass. Mycological Research, 102, 559-67.

Maurin, N., Rezanoor, H. N., Lamkadmi, Z., Some, A., \& Nicholson, P. (1995). A comparison of biological, molecular and enzymatic markers to investigate variability within Microdochium nivale (Fries) Samuels and Hallett. Agronomie, 15, 39-47.

McDermott, J. M., \& McDonald, B. A. (1993). Gene flow in plant patho-systems. Annual Review of Phytopathology, 31, 353-373.

McDonald, B. A. \& Linde, C. (2002). The population genetics of plant pathogens and breeding strategies for durable resistance. Euphytica, 124, 163-180.

Menzies, J. G., Bakkeren, G., Matheson, F., Procunier, J. D., \& Woods, S. (2003). Use of inter-simple sequence repeats and amplified fragment length polymorphisms to analyze genetic relationships among small grain-infecting species of Ustilago. Phytopathology, $93,167-175$.

Millar, C. S., \& Colhoun, J. (1966). Fusarium diseases of cereals: IV. Observations of 
Fusarium nivale on wheat. Transactions of the British Mycological Society, 52, 57-66.

Nei, M. (1973). Analysis of gene diversity in subdivided populations. Proceedings of the National Academy of Sciences of the United States of America, 70, 3321-3323.

Nicholson, P., Lees, A. K., Maurin, N., Parry, D. W., \& Rezanoor, H. N. (1996). Development of a PCR assay to identify and quantify Microdochium nivale var. nivale and Microdochium nivale var. majus in wheat. Physiological and Molecular Plant Pathology, $48,257-271$.

Nicholson, P., \& Parry, D. W. (1996). Development and use of a PCR assay to detect Rhizoctonia cerealis the cause of sharp eye- spot in wheat. Plant Pathology, 45, 872-83.

Nielsen, L. K., Justesen, A. F., Jensen, J. D., \& Jørgensen, L. N. (2013). Microdochium nivale and Microdochium majus in seed samples of Danish small grain cereals. Crop Protection, 43, 192-200.

Parry, D. W., Rezanoor, H. N., Pettitt, T. R., Hare, M. C., \& Nicholson, P. (1993). Analysis of Microdochium nivale isolates from wheat in the UK during 1993. Annals of Applied Biology, 126, 449-455.

Saitoh, K., Togashi, K., Arie, T., \& Teraoka, T. (2006). A simple method for a minipreparation of fungal DNA. Journal of General Plant Pathology, 72, 348-350.

Samuels, G. J., \& Hallett, I. C. (1983). Microdochium stoveri and Monographella stoveri, new combinations for Fusarium stoveri and Micronectriella stoveri. Transactions of the British Mycological Society, 81, 473-483.

Simpson, D. R., Rezanoor, H. N., Parry, D.W., \& Nicholson, P. (2002). Evidence for differential host preference in Microdochium nivale var. majus and Microdochium nivale var. nivale. Plant Pathology, 49, 261-268.

Stenglein, A. S., \& Balatti, A. P. (2006). Genetic diversity of Phaeoisariopsis griseola in Argentina as revealed by pathogenetic and molecular markers. Physiological and 
Molecular Plant Pathology, 68, 158-167.

Tanaka, F., Saito, I., Miyajima, K., Tsuchiya, S., \& Tsuboki, K.. (1983). Occurrence of thiophanate-methyl tolerant isolates of Fusarium nivale (= Gerlachia nivalis), a causal fungus of snow mold of winter wheat, in Japan (Abstract in Japanese). Japanese Journal of Phytopathology, 49, 565-566.

Terami, F., \& Kawakami, A. (2006). Distribution of two pink snow mold (Microdochium nivale) varieties in Hokkaido prefecture and diversity of their growth speed (Abstract in Japanese). Japanese Journal of Phytopathology, 72, 203.

Wollenweber, H. W, \& Reinking, O. A. (1935). Die Fusarien, ihre Beschreibung, Schadwirkung und Bekämfung. Paul Parey, Berlin, Germany, 355 pp.

Yeh, F. C., Yang, R. C., \& Boyle, T. (1999). POPGENE. Microsoft Windows-based freeware for population genetic analysis. Release 1.31. University of Alberta, Edmonton.

Yu, M. Y., Ma, B., Luo, X., Zheng, X., \& Xiaoyan, L. Y. (2008). Molecular diversity of Auricularia polytricha revealed by inter-simple sequence repeat and sequence-related amplified polymorphism markers, Current Microbiology, 56, 240-245.

Zietkiewicz, E., Raflaski, A., \& Labuda, D. (1994). Genome fingerprinting by simple sequence repeat (SSR)-anchored polymerase chain reaction amplification. Genomics, 20, $176-183$. 
Tables

Table 1 Population, location, number of isolates of Microdochium nivale and

Microdochium majus used in this study

\begin{tabular}{|c|c|c|c|c|}
\hline \multirow{2}{*}{ Population } & \multirow{2}{*}{ Location } & \multicolumn{3}{|c|}{ No. of isolates } \\
\hline & & Total & M. nivale & M. majus \\
\hline Tokachi & $\begin{array}{l}\text { Asyoro, Makubetsu, Memuro, Obihiro, } \\
\text { Shihoro, Shikaoi, Shintoku, Taiki, Toyokoro }\end{array}$ & 101 & 6 & 95 \\
\hline Abashiri & $\begin{array}{l}\text { Bihoro, Engaru, Ozora, Kunneppu, } \\
\text { Memanbetsu, Saroma }\end{array}$ & 33 & 1 & 32 \\
\hline Sorachi & Fukagawa, Iwamizawa, Naganuma & 19 & 0 & 19 \\
\hline Iburi & Abira, Date & 12 & 0 & 12 \\
\hline Shiribeshi & Kyogoku & 7 & 0 & 7 \\
\hline
\end{tabular}


Table 2 ISSR primers used in this study

\begin{tabular}{|c|c|c|c|}
\hline Primer & No. of amplified bands & No. of polymorphic bands & PPB $(\%)^{\mathrm{a}}$ \\
\hline$(\mathrm{ACA})_{6}$ & 13 & 12 & 92.3 \\
\hline$(\mathrm{GTG})_{5}$ & 9 & 8 & 88.9 \\
\hline
\end{tabular}

${ }^{a}$ Percentage of polymorphic bands 
Table 3 Haplotype distribution within five populations of Microdochium nivale and Microdochium majus using two ISSR markers

\begin{tabular}{|c|c|c|c|c|c|c|c|c|}
\hline \multirow{2}{*}{ Haplotype } & \multicolumn{5}{|c|}{ Population } & \multirow{2}{*}{ Total } & \multirow{2}{*}{$\begin{array}{c}\text { Microdochium } \\
\text { species }\end{array}$} & \multirow{2}{*}{ Binary code } \\
\hline & Tokachi & Abashiri & Sorachi & Iburi & Shiribeshi & & & \\
\hline H1 & 12 & 0 & 0 & 0 & 0 & 12 & M. majus & 01011010101010100000 \\
\hline $\mathrm{H} 2$ & 44 & 28 & 14 & 9 & 7 & 102 & M. majus & 01011010101010001000 \\
\hline $\mathrm{H} 3$ & 33 & 3 & 3 & 2 & 0 & 41 & M. majus & 01011010101010101000 \\
\hline $\mathrm{H} 4$ & 1 & 0 & 0 & 0 & 0 & 1 & M. nivale & 10100000000111001011 \\
\hline H5 & 4 & 0 & 0 & 1 & 0 & 5 & M. majus & 01011010101010000000 \\
\hline H6 & 1 & 0 & 0 & 0 & 0 & 1 & M. nivale & 10011000000111010111 \\
\hline $\mathrm{H} 7$ & 2 & 0 & 0 & 0 & 0 & 2 & M. majus & 01011011101010001000 \\
\hline $\mathrm{H} 8$ & 1 & 0 & 0 & 0 & 0 & 1 & M. nivale & 00111000010111011111 \\
\hline $\mathrm{H} 9$ & 1 & 1 & 0 & 0 & 0 & 2 & M. nivale & 00100110010111011111 \\
\hline $\mathrm{H} 10$ & 1 & 0 & 0 & 0 & 0 & 1 & M. nivale & 10011000000111011111 \\
\hline H11 & 1 & 0 & 0 & 0 & 0 & 1 & M. nivale & 00100010100111010111 \\
\hline $\mathrm{H} 12$ & 0 & 0 & 1 & 0 & 0 & 1 & M. majus & 01011010001010001000 \\
\hline $\mathrm{H} 13$ & 0 & 0 & 1 & 0 & 0 & 1 & M. majus & 01001010101010001000 \\
\hline $\mathrm{H} 14$ & 0 & 1 & 0 & 0 & 0 & 1 & M. majus & 01010010101010101000 \\
\hline
\end{tabular}


Table 4 Genetic diversity and structure of 165 Microdochium majus isolates in five populations using two ISSR markers

\begin{tabular}{|l|c|c|c|c|c|c|c|c|}
\hline Population & Isolates & $\mathrm{PPB}(\%)^{\mathrm{a}}$ & $A_{\mathrm{E}}{ }^{b}$ & $H_{\mathrm{E}}{ }^{\mathrm{c}}$ & $H_{T}{ }^{\mathrm{d}}$ & $H_{\mathrm{S}}{ }^{e}$ & $\mathrm{G}_{S T}{ }^{\mathrm{f}}$ & $\mathrm{Nm}^{\mathrm{g}}$ \\
\hline Tokachi & 95 & 15.0 & 1.071 & 0.041 & & & & \\
\hline Abashiri & 32 & 10.0 & 1.017 & 0.014 & & & & \\
\hline Sorachi & 19 & 15.0 & 1.029 & 0.023 & & & & \\
\hline Iburi & 12 & 10.0 & 1.028 & 0.022 & & & & \\
\hline Shiribeshi & 7 & 0.0 & 1.000 & 0.000 & & & & \\
\hline species level & - & 27.3 & 1.054 & 0.034 & 0.023 & 0.020 & 0.130 & 3.334 \\
\hline
\end{tabular}

${ }^{a}$ Percentage of polymorphic bands

${ }^{\mathrm{b}}$ Effective number of alleles per locus

${ }^{c}$ Nei's gene diversity

${ }^{\mathrm{d}}$ Total gene diversity of populations

${ }^{\mathrm{e}}$ Average gene diversity within populations

${ }^{\mathrm{f}}$ Coefficient of gene differentiation

${ }^{\mathrm{g}}$ Level of gene flow 
Table 5 Analysis of molecular variance (AMOVA) of 165 Microdochium majus isolates in five populations using two ISSR markers

\begin{tabular}{|c|c|c|c|c|c|}
\hline Source of variation & d.f. $^{\mathrm{a}}$ & MSD $^{\mathrm{b}}$ & $\begin{array}{c}\text { Variance } \\
\text { component }\end{array}$ & $\begin{array}{c}\text { Total } \\
\text { variance }\end{array}$ & P-value $^{\mathrm{c}}$ \\
\hline Among population & 4 & 1.53 & 0.05 & 13.26 & $<0.001$ \\
\hline Within population & 160 & 0.32 & 0.32 & 86.74 & $<0.001$ \\
\hline
\end{tabular}

\footnotetext{
${ }^{a}$ Degree of freedom

${ }^{\mathrm{b}}$ Mean squared diviation

${ }^{\mathrm{c}}$ Probabilities were calculated by 1023 random permutations of individuals across populations.
} 


\section{Figure}

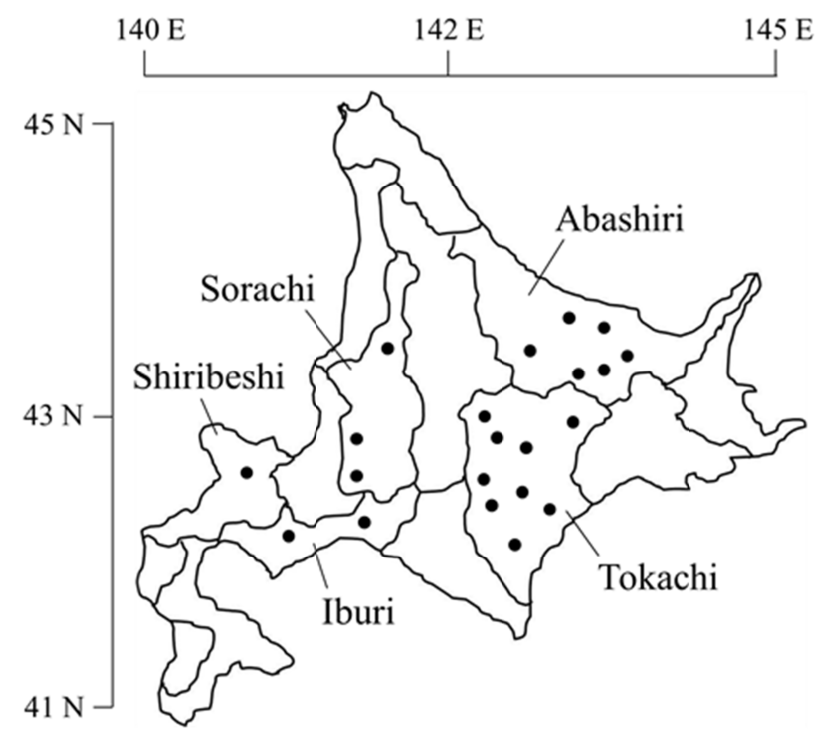

Fig. 1 Map showing geographical location of Microdochium nivale and Microdochium majus populations used in this study.

Five populations and location included them were represented by filling with gray and plotting with black respectively. 


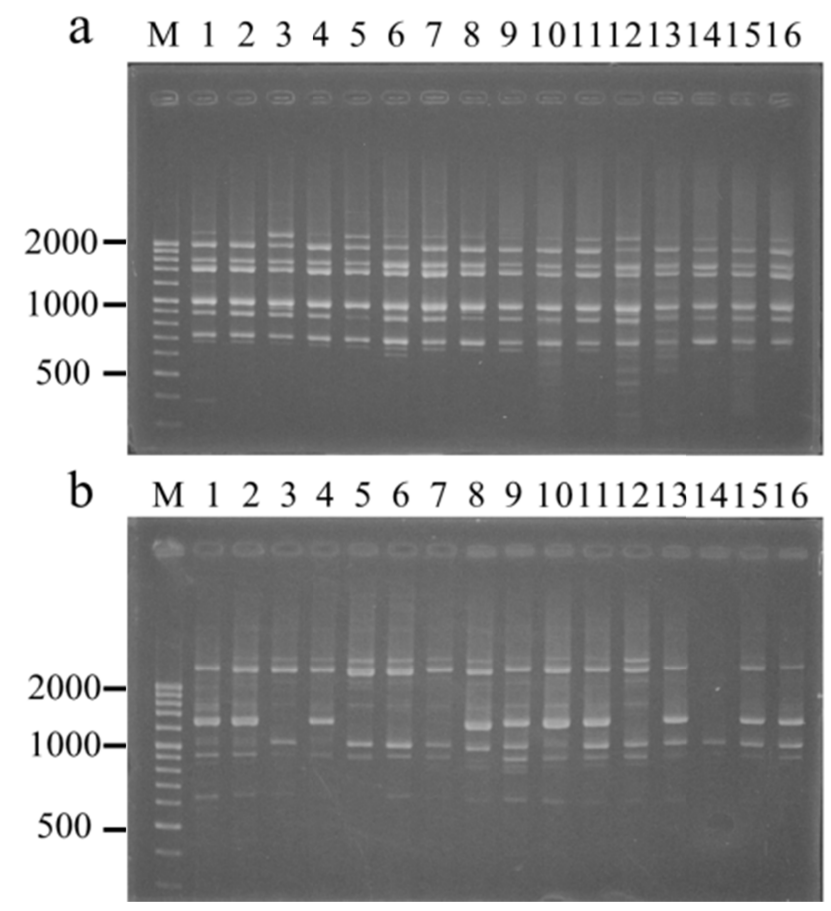

Fig. 2 Example of ethidium bromide-stained gel of PCR fragments obtained by amplification with ISSR primers (a) (ACA) $)_{6}$ and (b) (GTG) $)_{5}$.

Results of ISSR analysis of Microdochium majus 1-16: isolates of Microdochium majus. M: 100 bp DNA ladder. 


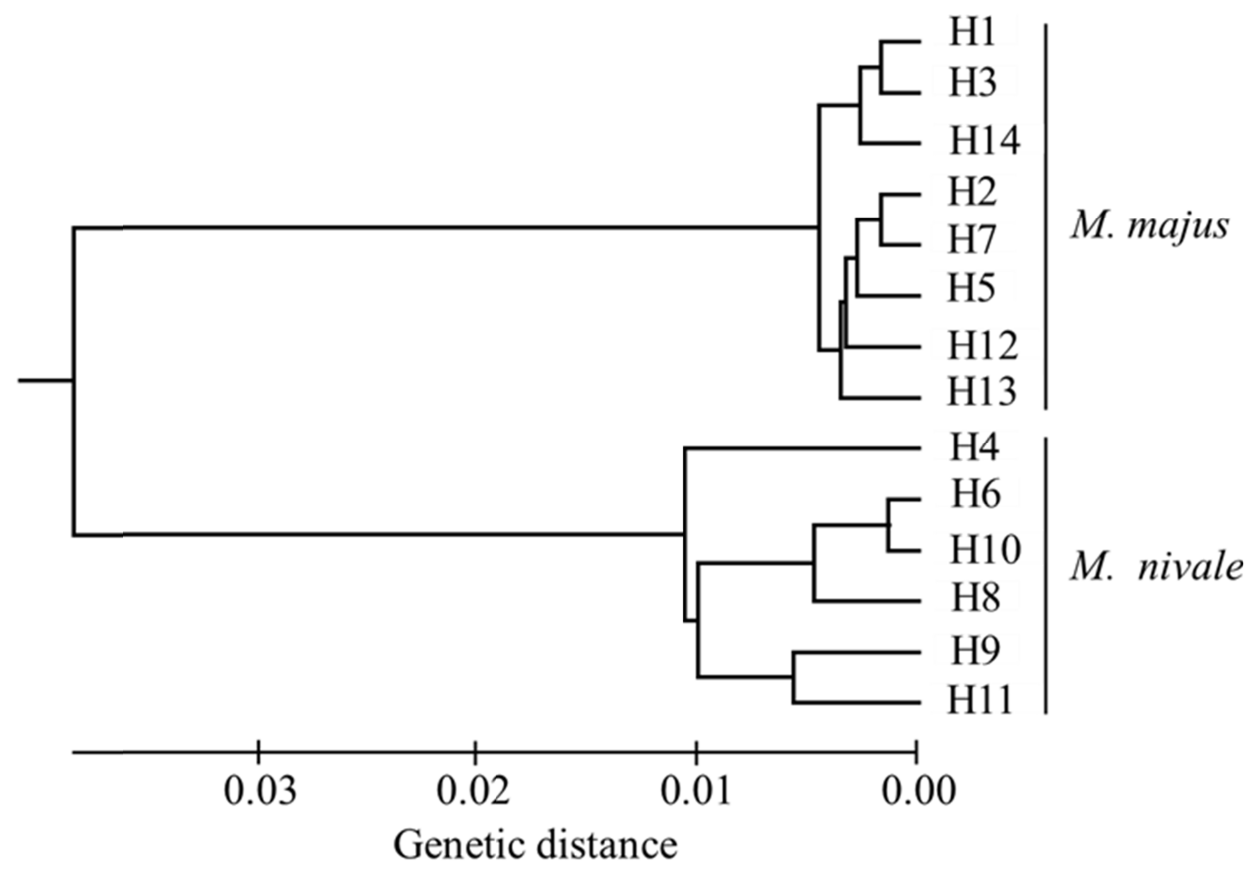

Fig. 3 Dendrogram of 14 haplotypes identified from 172 isolates of Microdochium nivale and Microdochium majus based on UPGMA cluster analysis using the program PHYLIP version 3.69 with genetic distances calculated from ISSR dates. 